\title{
Study on Speed Control Strategy of Brushless DC Motors Based on Fuzzy PID
}

\author{
Chunfeng Li ${ }^{1, *}$, Dandan Sun ${ }^{2}$ and Wusheng Tang ${ }^{3}$ \\ ${ }^{I}$ Electronic Information Engineering College of Changchun University, Changchun, 130022, China \\ ${ }^{2}$ Foreign Language College of Changchun University, Changchun, 130022, China \\ ${ }^{3}$ Mechanical and Vehicle Engineering College of Changchun University, Changchun, 130022, China
}

\begin{abstract}
Firstly, this article establishes the mathematical models and speed principles of brushless DC motors. Next, it designs fuzzy PID controllers and current adjustors based on the adjusting speed theory and characteristics of brushless DC motors, which form double closed-loops to achieve intellectualized adjustment of brushless DC motors, creating the best effects simultaneously.
\end{abstract}

Keywords: Brushless DC motor, fuzzy PID controller, speed control.

\section{INTRODUCTION}

In modern society, as devices are being transformed from electric energy to kinetic energy, motors are being widely used covering different areas of national economy closely concerned with our daily life. From the invention of the first motor till now, motors have been developed for more than 100 years. There are different types of motors now, such as asynchronous motors, synchronous motors and capacitance motors, which basically satisfy different conditions. In some situations, which need higher property index, the modern motors could not meet the needs, so brushless DC motors have been invented which may enlarge the space application of motors and have a wider application in fields such as national defense, chemistry, aerospace, automotive electronics, and domestic applications, etc. However, the brushless DC motors are complicated systems having strong coupling, more index, nonlinearity and time varying. In the traditional adjusting speed method, the requirement of rotation rate control cannot be satisfied, and the control accuracy and integration are not high, and hence, an accurate mathematical model is needed to establish for controlled objects. However, fuzzy PID rotation rate controllers are different from the traditional rotation rate controllers, in that: they don't need to make mathematical models for the controlled objects; their parameters and rules are made according to the knowledge and experience of system designers; and human operations are added properly, so that motors can achieve the best effects of rotation rate control in operation. So, this article will carry out a further study on intellectualized control of brushless DC motors' speed, that is the fuzzy PID control.

*Address correspondence to this author at No.6543, Weixing Road, Changchun city, China, Postcard: 130022, Tel: +86-0431-85250282;

E-mail: 107961758@qq.com

\section{MATHNATICAL MODEL OF BRUSHLESS DC MOTORS}

Stator winding phase voltage of brushless DC motors equals to the sum of voltage in equivalent resistance and induced EMF in stator winding; the equivalent circuit of brushless DC motors is shown as Fig. (1), its mathematical expression is:

$$
\begin{aligned}
& u_{A}=R i_{A}+(L-M) \frac{d i_{A}}{d t}+e_{A} \\
& u_{B}=R i_{B}+(L-M) \frac{d i_{B}}{d t}+e_{B} \\
& u C=R i_{C}+(L-M) \frac{d i_{C}}{d t}+e_{C}
\end{aligned}
$$

In this expression: $u_{A}, u_{B}, u_{C}$-phase voltage of motor stator winding;

$i_{A} 、 i_{B} 、 i_{C}$-phase current motor stator winding;

$e A, e_{B}, e^{e C}$ - back electromotive force of motor stator winding.

Transient power consumption when motors are operated is :

$p=J \Omega \frac{d \Omega}{d t}$

In the equation : $\Omega$-angle velocity of motors ;

$p$-power consumption of brushless DC motors. 


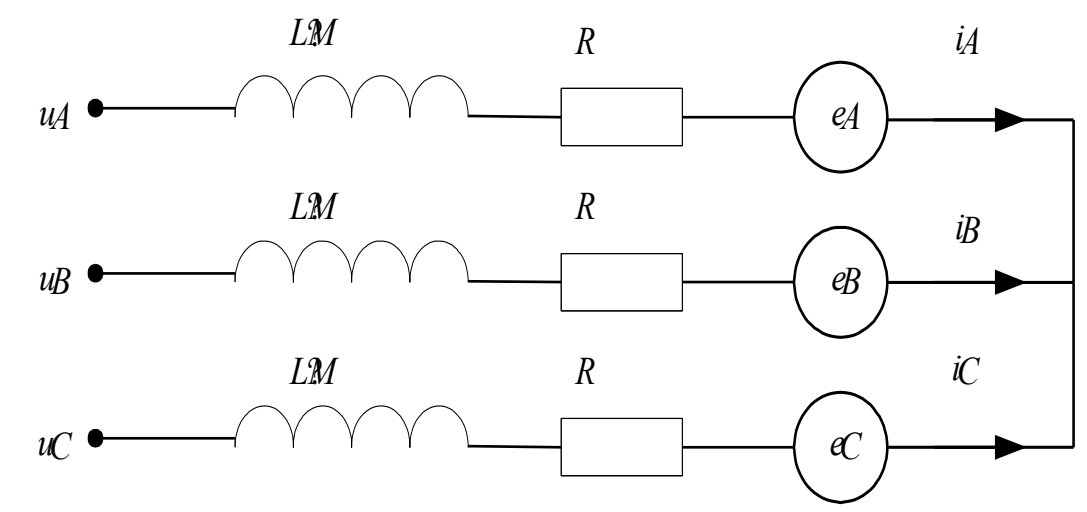

Fig. (1). Equivalent circuit of brushless DC motors.

The expression of electromagnetic torque $P_{e}$ is:

$T_{e}=\frac{E_{A i_{A}}+E_{B i_{B}}+E_{C} i_{C}}{\omega}$

In the expression: $E_{A}, E_{B}, E_{C}$-three-phase back EMF;

$\omega$-angle velocity of rotor. tion is:

The equation of brushless DC motors' mechanical mo-

$T_{e}-T_{L}-f \omega=J \frac{d \omega}{d t}$

In the equation: $T_{e}$-electromagnetic torque of motors;

$T_{L}$ - load torque of motors;

$J$-inertial moment of motors;

$f$ —damping coefficient of brushless DC motors.

\section{ADJUSTING SPEED THEORY OF BRUSHLESS DC MOTORS}

From the mathematical model of brushless DC motors, each phase back EMF of three-phase Y-shape stator winding is obtained as follows :

$E_{m}=N \cdot B \cdot l \cdot v=N \cdot B \cdot l \cdot \frac{n}{60} \cdot 2 \pi \cdot \tau$

In the equation : $l$-effective length of conductor incision magnetic field ;

$N$-equivalent number of windings in three-phase Yshape stator winding of brushless DC motors ;

$n$-rotating speed of brushless DC motors ;

$\tau$-polar distance of brushless DC motors ;

$B$-magnetic intensity of brushless DC motors' gas gap magnetic field.
Because the main magnetic flow in brushless DC motors is:

$$
\phi_{m}=\frac{B \cdot l \cdot 2 \pi \cdot \tau}{P_{n}}
$$

Put (2-22) into (2-21), each phase back EMF of brushless DC motors' stator winding can be obtained as follows:

$E_{m}=\frac{N \cdot p_{n}}{60} \cdot \phi_{m} \cdot n=K_{e} \cdot \phi_{m} \cdot n$

In this equation : $K_{e}=\frac{N \cdot p_{n}}{60}$-electric potential coefficient;

$p_{n}$ - polar logarithm of brushless DC motors.

Because stator winding have only 2 phases broken when motor operates in normal situation at any time in the opposite direction of flowing current, suppose the twophase average voltage on stator winding breakover is $V_{d}$, then the expression of voltage equilibrium equation is just as the following:

$V_{d}=2 E_{m}+\mathrm{Im}_{\mathrm{m}} \cdot R_{\Sigma}=2 K_{e} \cdot \phi_{m} \cdot n+\mathrm{Im}_{\mathrm{m}} \cdot R_{\Sigma}$

Reorganizing the rotation rate $n_{\text {in }}$ (2-24), the following expression of rotation rate is as following :

$n=\frac{V_{d}-\mathrm{I}_{\mathrm{m}} \cdot R_{\Sigma}}{2 K_{e} \cdot \phi_{m}}=\frac{V_{d}}{2 K_{e} \cdot \phi_{m}}-\frac{\mathrm{I}_{\mathrm{m}} \cdot R_{\Sigma}}{2 K_{e} \cdot \phi_{m}}$

In this equation, $R_{\Sigma}$ is the sum of equivalent resistance of two-phase stator winding in brushless DC motors and equivalent resistance through power tubes, that is, the total equivalent resistance of brushless DC motors return circuit. From the above deduced rotation rate equation of brushless DC motors, its rotation rate equation is basically found to be the same as the other rotation rate equation of direct current motors. Hence, the adjusting principles of brushless DC motors can be accomplished through adjusting voltage of stator winding [1]. 


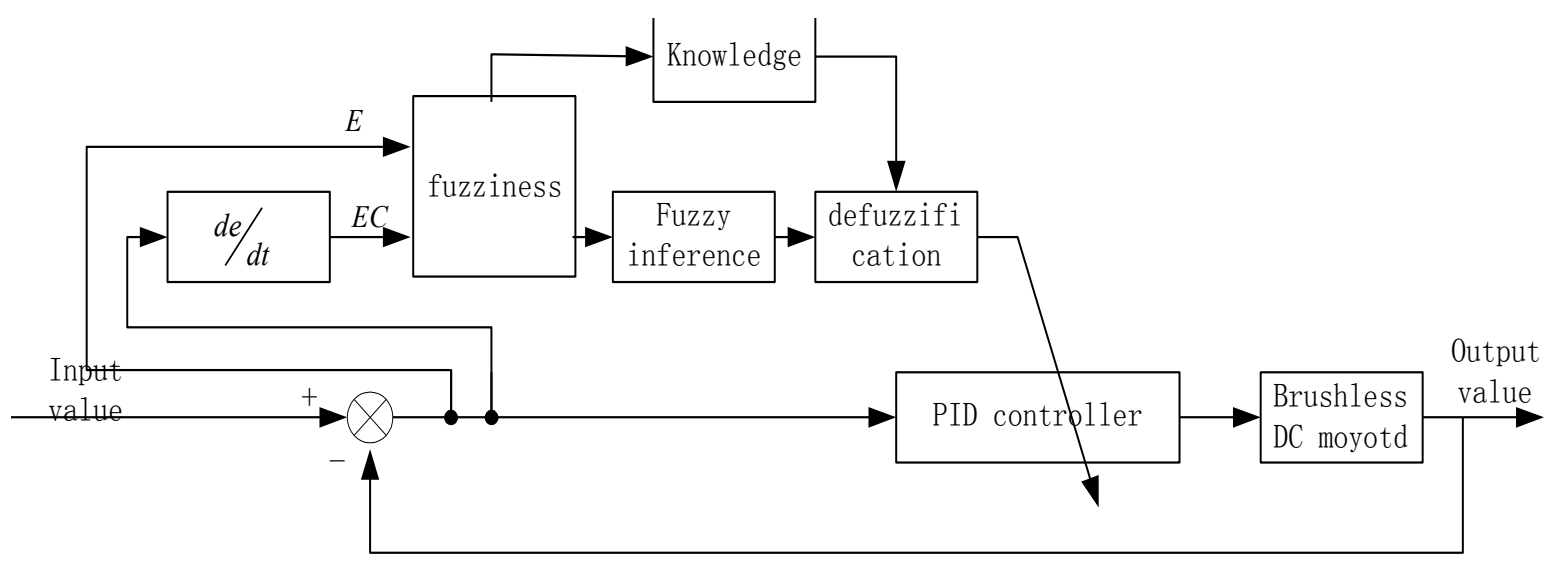

Fig. (2). Conceptual design of fuzzy rotation rate PID control.

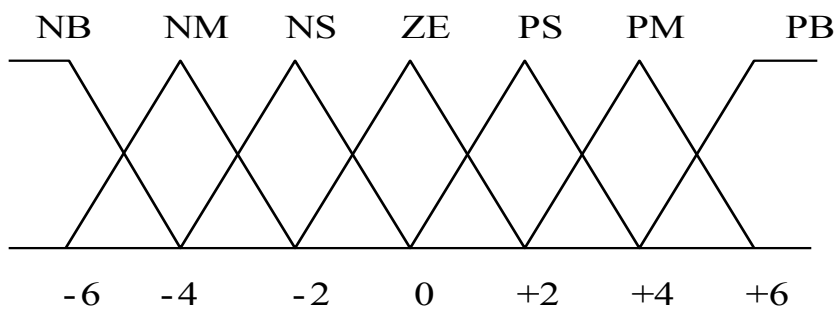

Fig. (3). Membership functions in fuzzy controller of brushless DC Motors.

\section{CONCEPTUAL DESIGN OF FUZZY ROTATION RATE PID CONTROL}

Schematic diagram in Fig. (2) shows conceptual design of brushless DC motors that is controlled by fuzzy PID controller in two-dimensional rotation rate. The essence of the design is to combine fuzzy control with traditional PID control. Speed variation $e$ and change rate of speed variation $e_{c}$ are taken as input value; and three parameters $k_{p}$ 、 $k_{i}$ and $k_{d}$ of PID, as linguistic output variables Table $\mathbf{1}$. According to different speed variation $e$ and change rate of speed variation $e_{c}$ in the rotation of motors, three parameters $k_{p}, k_{i}$ and $k_{d}$ of PID are being adjusted on line to make brushless DC motors to achieve good static-dynamic performance and adjustment of speed [2].

\section{ACCOMPLISHMENT OF DESIGN IN FUZZY RO- TATION RATE PID CONTROLLER}

From the functional Schematic diagram of fuzzy rotation rate PID controller, the practical discourse domains of speed variation $e$, change rate of speed variation $e_{c}$ and three parameters $k_{p} k_{i}$ and $k_{d}$ of PID are separated $\left[-M_{e}, M_{e}\right]$, $\left[-M_{e c}, M_{e c}\right],\left[-N_{k p}, N_{k p}\right],\left[-N_{k i}, N_{k i}\right],\left[-N_{k d}, N_{k d}\right]$, simultaneously their discourse domains of fuzzy subset are chosen as: $[-l,-l+1, \cdots, 0, l-1, a],[-y,-y+1, \cdots, 0, y-1, b]$, $[-z,-z+1, \cdots, 0, z-1, z],[-k,-k+1, \cdots, 0, k-1, k]$,

$[-e,-e+1, \cdots, 0, e-1, e]$, and their fuzzy subset are chosen as: $\{N B, N M, N S, Z O, P S, P M, P B\}$, function of membership degree chooses triangle function of membership degree which are distributed symmetrically and overlapped. So the triangular distribution function, which is taken as membership functions in fuzzy controller of brushless DC motors, is shown in Fig. (3).

From the knowledge of automatic control theory, we found that proportionality coefficient $k_{p}$, integral coefficient $k_{i}$ and differential coefficient $k_{d}$ play different roles in static-dynamic performance of controlled objects Table 2. For example, proportionality coefficient $k_{p}$ plays important role in increasing response speed and improving accuracy of system adjustment [3]. The role of integral coefficient $k_{i}$ is to eliminate steady-state error, whereas the role of differential coefficient $k_{d}$ is to restrain the variation of deviation. So, rule lists of fuzzy control PID are based on: controlling system, appropriate operation, self-adjustment and operation experiences of working members:

Through the previous induction of fuzzy control rule list on output value $k_{p} 、 k_{i}$ and $k_{d}$ of fuzzy rotation rate PID, their fuzzy relation is established. Through the process of defuzzification, an online adjusting PID controller that has accurate control value $k_{p} 、 k_{i}$ and $k_{d}$ is obtained to realize the intellectualized speed adjustment of brushless 
Table 1. Rule list of proportionality coefficient $k_{p}$ fuzzy control.

\begin{tabular}{|c|c|c|c|c|c|c|c|}
\hline$E C$ & NB & NM & NS & ZO & PS & PM & PB \\
\hline \hline NB & PB & PB & PM & PM & PM & PS \\
\hline NM & PB & PB & PM & PS & PS & ZO \\
\hline NS & PM & PM & PM & PS & ZO & NS & NM \\
\hline ZO & PM & PM & PS & ZO NM & NS & NM \\
\hline PS & PM & PS & ZO & NS & NM & NB \\
\hline PM & PS & ZO & NS & NM & NM & NB \\
\hline PB & ZO & ZO & NM & NB \\
\hline
\end{tabular}

Table 2. Rule list of integral coefficient $k_{i}$ fuzzy control.

\begin{tabular}{|c|c|c|c|c|c|c|c|}
\hline$E C$ & NB & NM & NS & ZO & PS & PM & PB \\
\hline NB & NB & NB & NM & NM & NM & NS & $\mathrm{ZO}$ \\
\hline NM & NB & NB & $\mathrm{NM}$ & NS & NS & $\mathrm{ZO}$ & $\mathrm{ZO}$ \\
\hline NS & NB & NM & NS & NS & $\mathrm{ZO}$ & PS & PS \\
\hline $\mathrm{ZO}$ & NM & NM & NS & $\mathrm{ZO}$ & PS & PM & PM \\
\hline PS & $\mathrm{NM}$ & NS & $\mathrm{ZO}$ & PS & PS & $\mathrm{PM}$ & PB \\
\hline $\mathrm{PM}$ & NS & $\mathrm{ZO}$ & PS & PS & $\mathrm{PM}$ & PB & PB \\
\hline PB & $\mathrm{ZO}$ & $\mathrm{ZO}$ & PS & PM & PM & PB & PB \\
\hline
\end{tabular}

Table 3. Rule List of differential coefficient $k d$ Fuzzy Control.

\begin{tabular}{|c|c|c|c|c|c|c|c|}
\hline$E C$ & NB & NM & NS & ZO & PS & PM & PB \\
\hline \hline NB & PS & NS & NB & NB & NB & NM \\
\hline NM & PS & NS & NB & NM & NM & NS \\
\hline NS & ZO & NS & NM & NM & NS & NS \\
\hline ZO & ZO & NS & NS & NS & NS & NS & ZO \\
\hline PS & ZO & ZO & ZO & ZO & PO & PS \\
\hline PM & PB & PS & PS & PS & PB & PS \\
\hline PB & PB & PM & PM & PM & PB \\
\hline
\end{tabular}

DC motors [4, 5]. Fuzzy decision-making adopt triangle functions of membership degree as weighting coefficient, and weighted average law method, which are concerned with systematic response proprieties, so decision-making output of fuzzy value can be obtained through the following equation:

$$
u^{*}=\frac{\sum_{i=1}^{m} k_{i} u_{i}}{\sum_{i=1}^{m} k_{i}}
$$


In the equation : $k_{i}(i=1,2,3, \cdots, m)$ is the weighting coefficient (Table 3).

But at the time of choosing membership functions as weighting coefficient, output mathematical expression is:

$$
u^{*}=\frac{\sum_{i=1}^{m} \mu_{\underline{A}}\left(u_{i}\right) \cdot u_{i}}{\sum_{i=1}^{m} \mu_{\underline{A}}\left(u_{i}\right)}
$$

\section{CONCLUSION}

Based on the Study on Speed Control Strategy of Brushless DC Motors Based on Fuzzy PID, we can conclude that speed control of brushless DC motors adopt fuzzy PID control whose effects are superior to traditional double closed-loop control, in that fuzzy PID control achieved intellectualization and integration. So, the previous study must supply help and reference for further study on brushless DC motors, and enlarge the application space of brushless DC motors simultaneously.

\section{CONFLICT OF INTEREST}

The author confirms that this article content has no conflict of interest.

\section{ACKNOWLEDGEMENTS}

We gratefully acknowledge the help and supervision in writing this article, of teachers in Innovation Center of Changchun University.

\section{REFERENCES}

[1] T. Jin, "Study on Adjusting Speed System of Sensorless Brushless DC Motors," Master thesis, Northwestern Polytechnical University, 2005.

[2] W. D. Qiao, "Adjusting speed system of PM brushless DC motors based on fuzzy PID control," Jiangsu Electrical Application, vol. 2008, no. 12, pp. 12-14, 2008.

[3] C. L. Xia, "Controlling System of Brushless DC Motors," Science Press, 2009.

[4] G. Liu, Z. Q. Wang, and J. C. Fang, "Control Strategy and Application of PM Brushless DC motors," Engineering Industry Press, 2008.

[5] D. S. Sun, and L. P. Bai, “Application of Fuzzy Self-adaptation PID Controller in Brushless DC Motors Control System," Electric Drive, vol. 39, no. 10, pp. 63-66, 2009. 